\title{
Effects of prepartum stocking density and a blind on physiological biomarkers, health, and hygiene of transition Holstein dairy cows
}

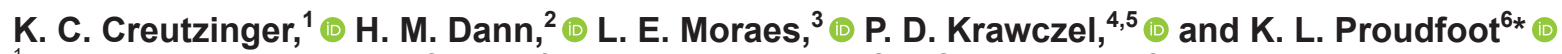 \\ ${ }^{1}$ Veterinary Preventive Medicine, College of Veterinary Medicine, The Ohio State University, Columbus 43210 \\ ${ }^{2}$ William H. Miner Agricultural Research Institute, Chazy, NY 12921 \\ ${ }^{3}$ Department of Animal Sciences, The Ohio State University, Columbus 43210 \\ ${ }^{4}$ Department of Agricultural Sciences, Faculty of Agricultural and Forestry, University of Helsinki, Fl-00014 Helsinki, Finland \\ ${ }^{5}$ Research Centre for Animal Welfare, Department of Production Animal Medicine, Faculty of Veterinary Medicine, University of Helsinki, 00014 , \\ Helsinki, Finland \\ ${ }^{6}$ Atlantic Veterinary College, University of Prince Edward Island, Charlottetown, PEI, C1A 4P3, Canada
}

\begin{abstract}
Many dairy cows succumb to disease after calving. Disease risk may be affected by the cows' social environment and ability to perform maternal behaviors. In nature, cattle isolate from others and find seclusion to give birth; these behaviors may be limited in indoor group pens and could potentially affect the cows' ability to cope. The aim was to determine whether stocking density and a physical blind in prepartum bedded-pack group pens affected physiological biomarkers, disease risk, and hygiene of peripartum dairy cows. A randomized complete block designed with a $2 \times 2$ factorial arrangement of treatments was used. Approximately 3 wk before calving, 374 cows (primiparous $=127$; multiparous $=247$ ) were assigned randomly to 1 of 4 treatment pens with the following 2 factors: (1) high versus low stocking density (7.7 to $12.9 \mathrm{~m}^{2}$ vs. 15.4 to 25.8 $\mathrm{m}^{2}$ lying space per cow), and (2) presence or absence of a blind. The blind was created using plastic road barriers and plywood, a steel gate, and shade cloth. After calving, cows were moved into a freestall pen and milked 3 times per day. Blood was sampled on the day of enrollment (baseline; $-24 \mathrm{~d}$ ) and approximately -14 , $-7,3,7,10$, and $14 \mathrm{~d}$ relative to calving, to measure inflammatory (haptoglobin) and metabolic (nonesterified fatty acids and $\beta$-hydroxybutyrate) biomarkers. $\beta$-Hydroxybutyrate $(\geq 1.2 \mathrm{mmol} / \mathrm{L})$ was used to diagnose subclinical ketosis. Vaginal discharge was scored $3,7,10$, and $14 \mathrm{~d}$ after calving, to diagnose metritis (none, mild, or severe). Hygiene was scored on -24 , -14 , and $-7 \mathrm{~d}$ before calving. Before calving, haptoglobin was lower in pens with a blind. After calving, cows in pens with low stocking density before calving tended
\end{abstract}

Received April 15, 2020.

Accepted September 7, 2020.

*Corresponding author: kproudfoot@upei.ca to be at greater odds of being diagnosed with metritis. Cows were more likely to have poorer hygiene scores in high stocking density pens. No treatment effects were detected for pre- and postpartum nonesterified fatty acids, $\beta$-hydroxybutyrate, postpartum haptoglobin, or subclinical ketosis. Results suggest that the provision of a blind and lower stocking density may be beneficial for reducing inflammation before calving. However, low prepartum stocking density might increase the odds of metritis after calving. Although the reason for this paradox is unclear, the effects of prepartum stocking density may require further exploration.

Key words: animal welfare, transition, stocking density

\section{INTRODUCTION}

Dairy cows are at high risk of becoming ill after calving (McArt et al., 2012; Genís et al., 2018). Common diseases that occur within the few weeks after calving include metritis (uterine inflammation; Giuliodori et al., 2013) and subclinical ketosis (McArt et al., 2012). Changes in physiological indicators are evident in cows at risk for these diseases before and after calving, including increased circulating nonesterified fatty acids (NEFA; Ospina et al., 2010a), BHB (McArt et al., 2012), and haptoglobin (Huzzey et al., 2009). Continued problems with transition cow disease suggest we are missing important factors related to the housing of periparturient cows, which could affect their ability to cope with physiological challenges during this period.

Some diseases and metabolic biomarkers have been associated with cows' social environment before and after calving. For example, Miltenburg et al. (2018) found that increases in prepartum stocking density in freestalls ( 80 vs. $120 \%$ freestall stocking density and 90 vs. $45 \mathrm{~cm}$ feedbunk space) slightly increased hepatic concentration of triacylglycerol during the postpartum 
period but had no effects on metabolic or immune responses, uterine health, or milk yield. Comparatively, Huzzey et al. (2012) used a more extreme overstocking treatment at double the recommended feed bunk and lying stall density (200\% stocking: 0.5 lying stalls per cow and $34.5 \mathrm{~cm}$ linear feed bunk space per cow), which resulted in higher circulating NEFA compared with $100 \%$ stocking (1 lying stall per cow and 68.5 $\mathrm{cm}$ linear feed bunk space per cow). Other research using less dramatic increases in stocking density has not found effects on physiology and health (e.g., Silva et al., 2014). Collectively, these studies suggest that dairy cows may be resilient to some alterations in their social environment, but dramatic increases in stocking density can alter physiologic biomarkers linked to poor health outcomes after calving.

The majority of studies to date assessing the effects of space allowance on cow health have used dairy cows kept in freestall pens before calving. According to a recent US survey, $58.7 \%$ of dairy producers reported housing prepartum cows in group bedded packs before calving (USDA, 2016); this type of housing may allow cows more freedom of movement, but stocking density may be more difficult to assess, because the system lacks defined lying spaces, as there are in freestall pens. For example, $100 \%$ stocking density usually means 1 cow to 1 freestall or unit of feeding space, but the same unit of space is not well defined for bedded packs. Thus, no clear evidence-based recommendations exist for lying space allocations for preparturient animals kept in bedded-pack pens. It may also be more challenging to keep bedded-pack pens clean, adding an additional challenge to minimizing disease risk for preparturient animals. Lying environments are the primary source of cow contact with moisture and manure, and, in prepartum cows, insufficient disinfection between calvings may contribute to increased disease risk (Elbers et al., 1998). The effects of stocking density on cow cleanliness and health outcomes in group bedded packs remains unclear.

Limited space in prepartum bedded-pack pens may reduce cows' ability to perform motivated maternal behaviors. As labor approaches, additional space may be required, as cows are motivated to perform exploratory and separation behavior in the day before giving birth in both outdoor (Lidfors et al., 1994) and indoor settings (Proudfoot et al., 2014a,b). Providing a blind in group pens may allow cows to separate from penmates despite a lack of space (Rørvang et al., 2018). In other mammals, an inability to perform maternal behaviors can result in increased signs of stress. For example, sows in farrowing crates that are unable to perform nest-building behavior before parturition have increased respiration rates (Heckt et al., 1988) and plasma cortisol (Lawrence et al., 1997). Social stressors may influence disease risk in farm animals (Proudfoot and Habing, 2015), but no work to our knowledge has assessed whether limiting the ability to perform maternal behaviors can have downstream effects on health outcomes in dairy cows.

The objectives of this study were to determine the effects of stocking density (lying space) and the provision of a blind for shelter in prepartum group bedded-pack maternity pens on cow hygiene, physiological indicators of inflammation (haptoglobin), and metabolic health (NEFA and BHB), as well as some disease outcomes (subclinical ketosis and metritis) during the transition period.

\section{MATERIALS AND METHODS}

This study was conducted at William H. Miner Agricultural Research Institute (Chazy, NY) between June 2016 and June 2017. The study protocol was approved by the William H. Miner Agricultural Research Institutes Animal Care and Use Committee (ACUC \# 2016AUR05).

\section{Animals, Housing, and Feeding}

A total of 374 Holstein dairy cows (nulliparous = 127 , primiparous $=102$, multiparous $=145$ ) were enrolled in the study $-21 \pm 3$ d relative to their projected calving date (actual: $23.6 \pm 5.8 \mathrm{~d}$; range $4-41 \mathrm{~d}$ before screening using exclusion criteria described below). Throughout this paper, we refer to primiparous cows as animals that are experiencing the transition period (both pre- and postpartum) for the first time.

At enrollment, cows were moved into 1 of 4 sawdustbedded-pack pens (Figure 1). Feed bunk alleys (9.8 m wide $\times 4.3 \mathrm{~m}$ long) consisted of grooved concrete. Pens were dynamic, with new cows enrolled weekly based on their expected calving date and removed within $8 \mathrm{~h}$ after calving. The bedded pack received clean sawdust every other day (enough sawdust to make the bedded pack visibly clean), and all sawdust was removed and replaced approximately once every 3 wk. Each pen was equipped with 12 individual feeding bins (Calan Broadbent Feeding System, American Calan Inc., Northwood, $\mathrm{NH}$ ). Cows were assigned to 1 individual bin (1 bin per cow). Stocking density at the feedbunk was kept constant for all treatments $(0.76 \mathrm{~m}$ per cow $)$ so that any effects of stocking density were attributed to changes in lying space and not to alterations in feeding behavior.

To access feed in the bins, cows placed their heads over a feed gate so that a magnet in their collar would 
unlock the corresponding gate. Animals were either previously trained to use the individual feeding bins or, if they were unfamiliar with the bins, underwent a 5 -d period of training to the feeding bins within 1 mo before study enrollment. Training to individual feeding bins occurred over $5 \mathrm{~d}$ : $\mathrm{d} 1$, bin gates remained open and all animals had access to all feeding bins; $d$ 2, bin gates were closed but unlocked and all animals had access to all feeding bins; $\mathrm{d} 3$ to 5 , bin gates were locked and animals could only unlock the gate to their corresponding collar. Animals were encouraged to use the feeding bins by trainers coaxing them in gently with hay 4 times per day.
Cows remained in the bedded-pack pen to give birth. Within $8 \mathrm{~h}$ after calving, cows were moved into a freestall pen containing both postpartum (0 to 14 DIM) and special needs or hospital cows. The pen was equipped with 34 freestalls ( $1.3 \mathrm{~m}$ wide, $2.6 \mathrm{~m}$ long, and $1.3 \mathrm{~m}$ high at the neck rail) and 47 headlocks $(0.6$ $\mathrm{m}$ wide). Median stocking density of the freestall pen over the course of the experiment was $105.9 \% \pm 14.9$ (median $\pm \mathrm{SD}$ ). Stocking density was calculated by the number of cows/number of stalls $\times 100$. Stall beds were covered with 1.7-m-long Animattress mattresses (Animat, Sherbrook, SQ, Canada), covered once weekly with approximately $10 \mathrm{~kg}$ of kiln-dried sawdust. Soiled
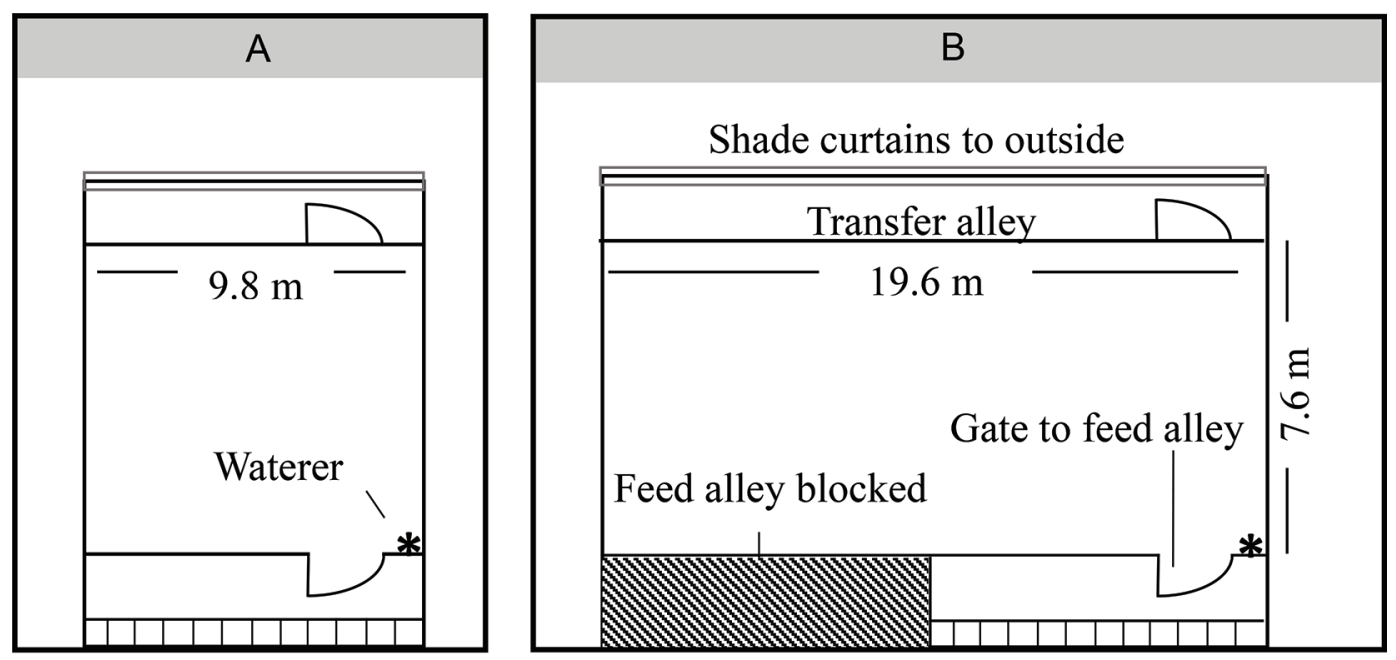

Individual feed bins
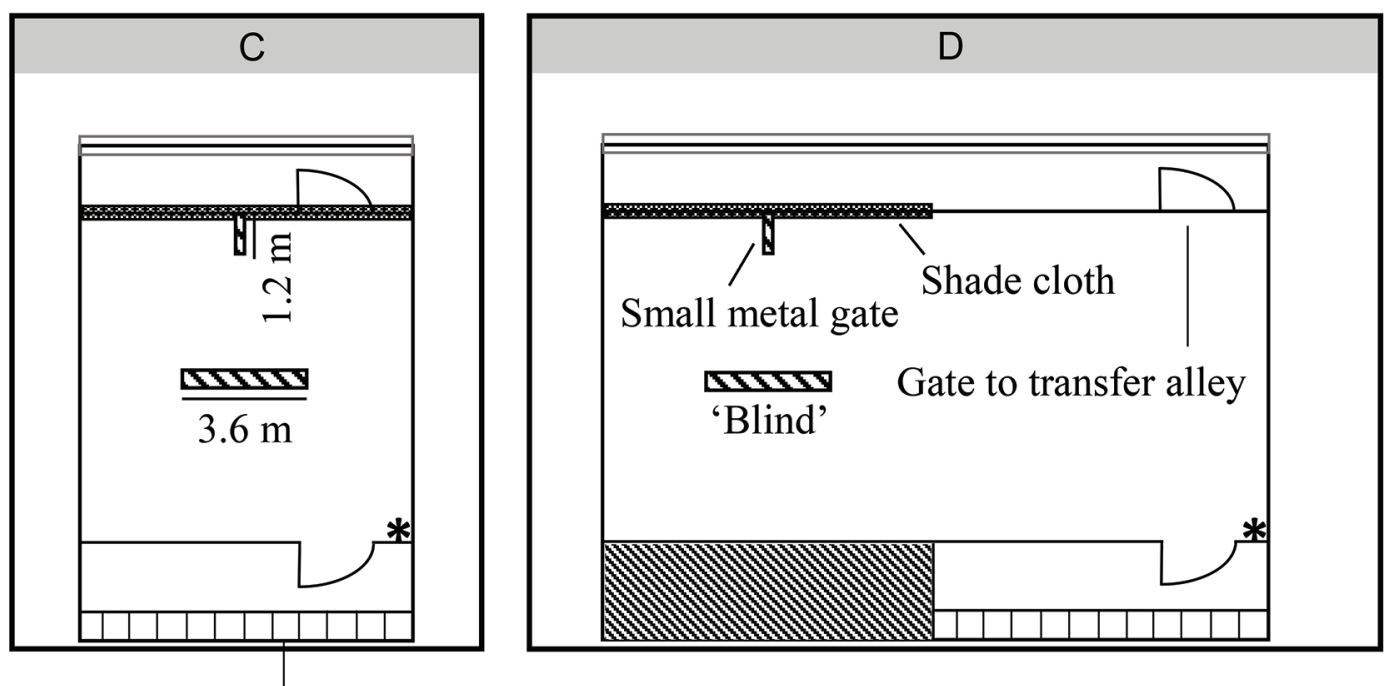

Feed alley

Figure 1. Design of treatment pens used in the experiment: (A) high stocking density without a blind, (B) low stocking density without a blind, (C) high stocking density with a blind, and (D) low stocking density with a blind. In pens with a blind, the blind was positioned $3.96 \mathrm{~m}$ from the back gate and $3.07 \mathrm{~m}$ from the side gate of the pen; in addition, a shade cloth was fitted around the gate separating the pen from the transfer alley $(1.52 \mathrm{~m}$ high $\times 9.8 \mathrm{~m}$ wide), and a 1.2 -m metal gate was positioned in the center of the pen perpendicular to the blind. 
bedding was removed, and clean sawdust bedding was redistributed across the mattress at the start of each milking (3 times daily). Crossover alleys consisted of grooved concrete ( 1 at either end of the pen); rubber was present on all other flooring (Animat). Alleys were scraped every $2 \mathrm{~h}$ with an automatic scraper system (Houle, Drummondville, QC, Canada). Cows were milked 3 times per day at approximately $0100 \mathrm{~h}, 0900$ $\mathrm{h}$, and $1700 \mathrm{~h}$ in a double-12 parallel parlor (Xpressway Parallel Stall System; Bou-Matic, Madison, WI).

Before calving, a TMR was offered once per day at approximately $0900 \mathrm{~h}$. Feed availability was monitored every 4 to $6 \mathrm{~h}$ to ensure that animals had constant access to feed. Target refusal of TMR was 4.5 to 6.8 $\mathrm{kg}$ per animal. Additional feed was added to individual feeding bins as needed in $4.5-\mathrm{kg}$ increments. Water was available ad libitum via 1 waterer per treatment pen. After calving, a TMR ration was offered once per day at approximately $0700 \mathrm{~h}$ to achieve $5 \%$ refusals. Feed was manually pushed to the feed bunk 6 times daily. Water was available ad libitum in 2 water troughs (50 $\mathrm{cm}$ wide, $152 \mathrm{~cm}$ long), 1 at each end of the pen, located in the cross alleys.

\section{Experimental Design}

To determine the effects of 2 factors (stocking density and the provision of a blind in the pen) on our outcome measurements, a randomized complete block design with a $2 \times 2$ factorial arrangement of treatments was used. The $2 \times 2$ factorial arrangements of treatments resulted in 4 pen types: (1) high stocking density with blind, (2) low stocking density with blind, (3) high stocking density without blind, and (4) low stocking density without blind. To create the 2 different stocking densities, approximately the same number of cows (6 to 10 cows) were included in 2 pens of different size: high stocking density pens had $7.9 \times 9.8 \mathrm{~m}$ of lying space (77.4 $\mathrm{m}^{2}$ total space; mean $9.7 \mathrm{~m}^{2}$ bedded-pack lying space per cow), whereas low stocking density pens had $7.9 \times 19.6 \mathrm{~m}$ of lying space $\left(154.1 \mathrm{~m}^{2}\right.$ total space; mean $19.3 \mathrm{~m}^{2}$ bedded-pack lying space per cow; see Figure 1).

The blind consisted of Jersey-style road barriers (Traffic Safety Store, West Chester, PA), which were $3.7 \mathrm{~m}$ long $\times 0.6 \mathrm{~m}$ wide at the base, narrowing to 2.5 $\mathrm{cm}$ at the top, $\times 1.5 \mathrm{~m}$ high (Figure 2 ) and positioned $4 \mathrm{~m}$ from the back gate and $3 \mathrm{~m}$ from the side gate of the pen. To create additional seclusion for the cows in the blind treatment, pens were fitted with black shade cloth around the gates on one side of the pen $(1.5 \mathrm{~m}$ high $\times 9.8$ wide), and a 1.2 -m steel gate positioned in the center of the gate between the pen and the transfer alley.
At enrollment, animals were balanced for parity (primiparous or multiparous) and assigned to 1 of the 4 treatment pens based on expected calving date, to keep a consistent number of animals in each pen. Once weekly, groups of 1 to 6 cows (mean \pm SD: $2.2 \pm 1.1$ cows) were moved into the 4 treatment pens to reestablish the desired stocking density. Due to the dynamic nature of maternity pens and fluctuations in expected calving dates, we were not always able to meet desired stocking densities following the removal of animals from the pen after calving. Study animals were enrolled based on their calving dates, and non-study animals were entered in the pens as fillers, when necessary, in an attempt to stay within the desired range of stocking densities for each treatment (low stocking density = 15.4 to $25.8 \mathrm{~m}^{2}$ bedded-pack lying space per cow; high stocking density $=7.7$ to $12.9 \mathrm{~m}^{2}$ of target bedded-pack lying space per cow; Figure 3).

To avoid location bias, despite pens being identical in design, we established new treatment pens and randomly altered the location for each treatment to allow each combination of treatments to be placed at all possible locations of the larger bedded-pack area. New treatment pens were established 4 times over the course of the study, resulting in a total of 4 periods (mean \pm SD: $12 \pm 3 \mathrm{wk}$ ), and their location within the bedded pack was moved. Location was never repeated for any treatment pen during the experiment. A total of 16 replicates were created $[4$ periods and 2 pens per factor (stocking density and blind) per period]. The number of cows per treatment pen was calculated daily during the prepartum period, using enrollment and calving dates. Stocking density (defined as square meters of lying space per cow) was calculated as the total bedded-pack

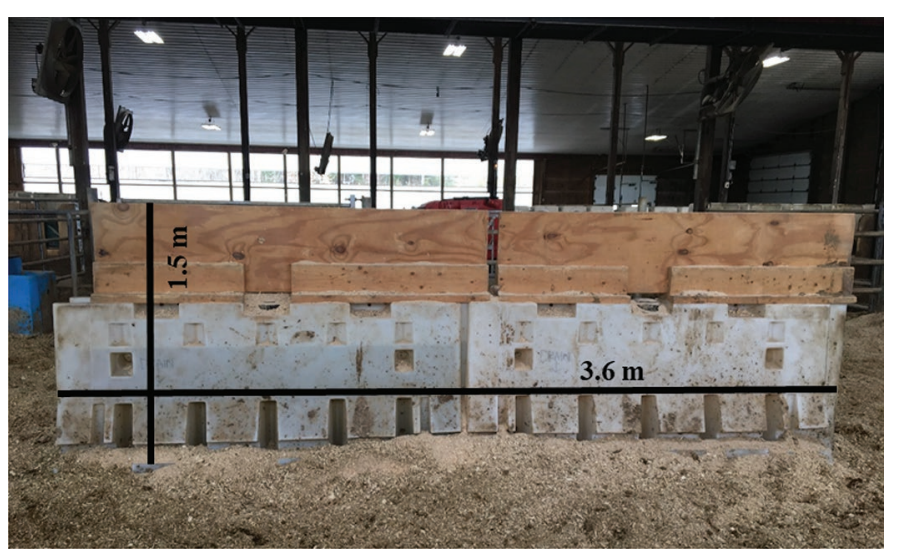

Figure 2. Image of the blind used in the experiment. The blind was built using 2 Jersey-style road barriers filled with water and a plywood addition $(3.66 \mathrm{~m}$ long $\times 0.61 \mathrm{~m}$ wide at the base, narrowing to $2.54 \mathrm{~cm}$ at the top $\times 1.52 \mathrm{~m}$ high). 
space per treatment pen divided by number of cows in the pen.

\section{Serum Biomarkers}

A subsample of animals $(\mathrm{n}=206$; primiparous $=$ 82; multiparous $=124$ ) was selected randomly for blood analysis. The subsampling method was a random sample stratified by replicate and parity using the SURVEYSELECT procedure in SAS (version 9.4, SAS Institute Inc., Cary, NC).

Blood samples were taken from the coccygeal vein or artery of all cows on the day of enrollment $(-23.6 \pm$ 5.8) and $-14 \pm 3,-7 \pm 3,3,7,10$, and $14 \mathrm{~d}$ relative to calving into BD Vacutainer tubes (BD Diagnostics, Franklin Lakes, NJ). Blood sampling occurred at approximately $0700 \mathrm{~h}$ on each day. To facilitate prepartum blood sampling, cows were moved from their home pens into a holding area, where they were moved through a chute using low-stress handling methods. To collect postpartum blood samples, cows were secured in a freestall they were occupying or gently moved into an unoccupied stall. After collection, blood was centrifuged at $4^{\circ} \mathrm{C}$ at $1,200 \times g$ for $20 \mathrm{~min}$, and serum was extracted using a pipette, divided into five $1-\mathrm{mL}$ aliquots and stored in a $-20^{\circ} \mathrm{C}$ freezer until further processing. Biomarkers of interest included indicators of inflammation (haptoglobin) and metabolic health (NEFA and BHB). Serum chemistry analyses for NEFA and BHB were conducted at the Animal Health Diagnostic Center, Cornell University (Ithaca, NY). Serum concentrations of NEFA and BHB were measured by colorimetric enzymatic assay. All spectrophotometric measurements were conducted using Roche Modular P Chemistry Analyzer (Roche Diagnostics, Indianapolis, IN). Cows with $\mathrm{BHB} \geq 1.2 \mathrm{mmol} / \mathrm{L}$ at 1 or more of the 4 postpartum samples were classified as having subclinical ketosis (McArt et al., 2012).

Haptoglobin was analyzed using a colorimetric assay (Tri-Delta Development Ltd., Maynooth, Ireland). Intra- and interassay coefficients of variation were $3.56 \%$ and $8.96 \%$, respectively. The colorimetric assay was performed according to the procedures provided by the manufacturer (Tri-Delta PHASE haptoglobin assay, catalog number TP-801; Tri-Delta Development Ltd.). Plate absorbances were read in a microplate reader (Synergy 2; BioTek Instruments Inc., Winooski, VT) at $630-\mathrm{nm}$ optical density.

\section{Body Condition Score}

All cows were scored for body condition on the day of enrollment into the study (approximately $3 \mathrm{wk}$ before calving), once weekly before calving, within $24 \mathrm{~h}$

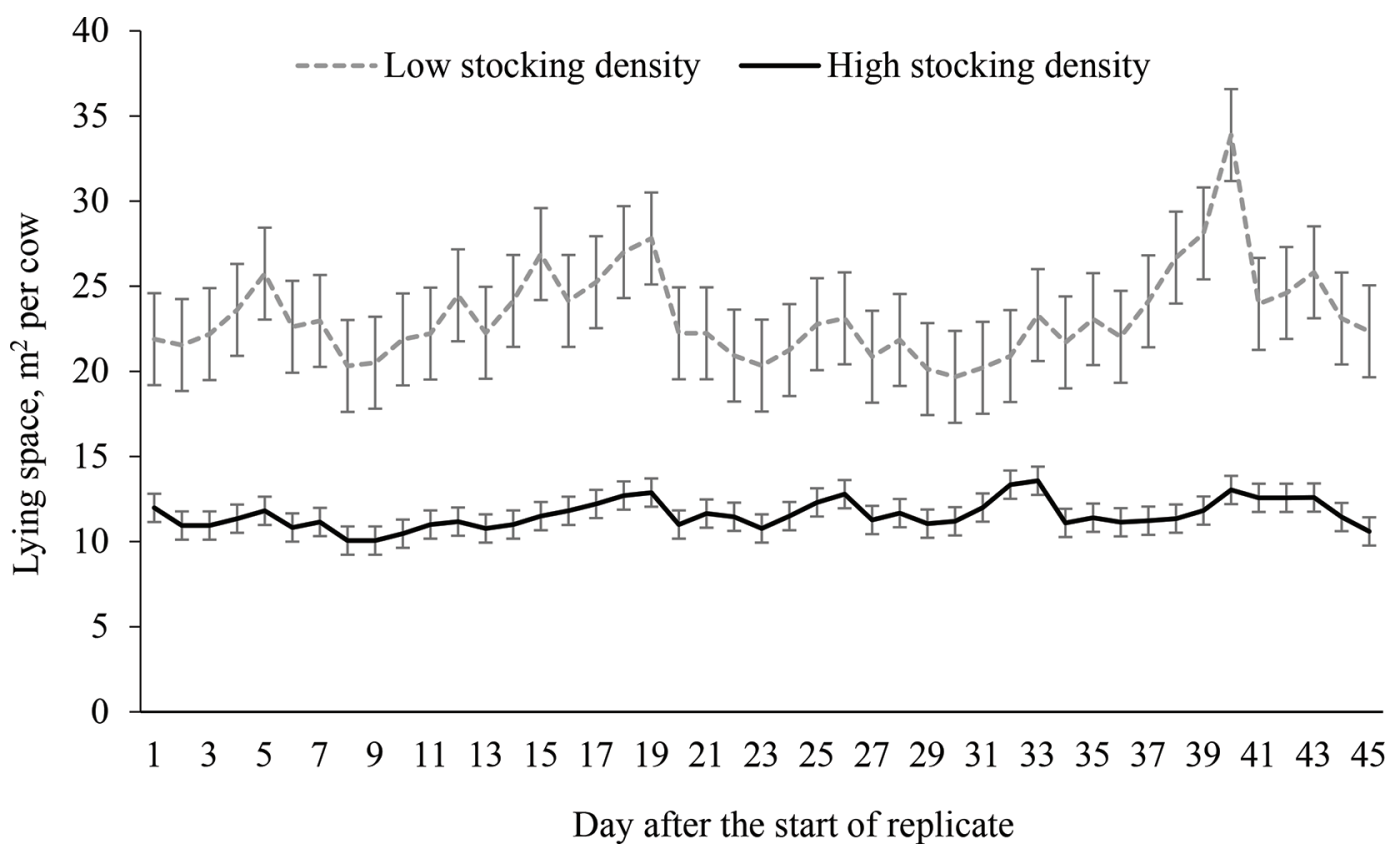

Figure 3. Mean \pm pooled SD of actual stocking density (lying space per cow, $\mathrm{m}^{2}$ ) in prepartum pens across replicates $(\mathrm{n}=16$; low stocking density $=8$ pens; high stocking density $=8$ pens). Low stocking density $=$ cows housed in prepartum pens with target of 15.4 to $25.8 \mathrm{~m}^{2}$ of bedded-pack lying space per cow (actual $=23.1 \pm 5.2 \mathrm{~m}^{2}$ of lying space per cow); high stocking density = cows housed in prepartum pens with target of 7.7 to $12.9 \mathrm{~m}^{2}$ of bedded-pack lying space per cow (actual $=11.7 \pm 2.3 \mathrm{~m}^{2}$ of lying space per cow). 
after calving, and 2 wk after calving for a subsample of animals by 2 trained observers (interobserver reliability was evaluated by kappa coefficient using the FREQ procedure of SAS; $\kappa \geq 0.76$ ) using the scoring system described by Ferguson et al. (1994).

\section{Hygiene and Disease Data Collection}

Before calving, hygiene was scored weekly by 2 observers (interobserver reliability was evaluated by kappa coefficient using the FREQ procedure of SAS; $\kappa \geq 0.79)$ for each animal on a 1-to-4 scale using the University of Wisconsin-Madison Hygiene Scoring Card (Cook, 2007), where little or no manure above the coronary band $=1$; small amounts of manure above the coronary band $=2$; distinct manure above the coronary band with visible hair $=3$; and solid manure extending high up the leg $=4$.

Because calving assistance (dystocia) may affect uterine health after calving, calving score was assigned for each cow using a 5 -point scoring system $(1=$ no assistance, $2=$ calf pull by hand, $3=$ calf pull with chains, $4=$ calf pull with calf jack, $5=$ cesarean section). Unassisted calving refers to a calving score of 1 , and assisted calving refers to a calving score of 2 or 3 . No animals in this study received a calving score of 4 or 5. Retained placenta was diagnosed by farm personnel and was defined as failure to release fetal membranes within $24 \mathrm{~h}$ of calving.

To diagnose metritis, vaginal discharge (VD) score was recorded for each cow on d 3, 7, 10, and 14 after calving by 2 trained technicians from 1000 to 1130 $\mathrm{h}$. To reduce the invasiveness of the examinations, a Metricheck device (Simcro Limited, Hamilton, New Zealand) was used. Before inserting the Metricheck into the vagina, the vulva and perineum were cleaned using $2 \%$ chlorhexidine and paper towel to remove fecal and other organic material. Once clean, the vulva was dried with a dry paper towel, and the Metricheck was inserted up to the point of the cervix. Upon reaching the cervix, the device was retracted from the vagina upward at a $45^{\circ}$ angle. The appearance and smell of the VD contained in the Metricheck cup was scored on a 0-to-4 scale (Huzzey et al., 2009) where no mucus or clear mucus $=0$; red or brown mucus, cloudy mucus, or mucus with flecks of pus without foul smell $=1$; mucopurulent $(\leq 50 \%$ pus present) and foul smelling $=$ 2 ; purulent ( $\geq 50 \%$ pus present) and foul smelling $=3$; and putrid (red or brown color, watery, foul smelling) $=4$. The Metricheck was cleaned using a $2 \%$ chlorhexidine solution between each cow. Rectal temperatures were taken daily during morning examinations, using a digital thermometer (GLA M7000 Digital Thermom- eter, GLA Agricultural Electronics, San Luis Obispo, CA).

Severe metritis was defined by the cow exhibiting at least $1 \mathrm{VD}$ score of 4 and a recording of a fever $\left(\geq 39.5^{\circ} \mathrm{C}\right)$ within $2 \mathrm{~d}( \pm)$ of the VD score of 4 . Mild metritis was defined by cows having at least $1 \mathrm{VD}$ score of 2,3 , or 4 . Cows classified as having mild metritis may or may not have presented a fever. Cows were classified as no metritis if they had a maximum VD score of 1 regardless of rectal temperature.

\section{Exclusion Criteria}

A total of 50 cows were excluded from analysis based on exclusion criteria defined before the start of the experiment. Cows were excluded from analysis if they aborted $(\mathrm{n}=1)$, had twins $(\mathrm{n}=9)$, were not pregnant $(\mathrm{n}=2)$, failed to eat from Calan bins $(\mathrm{n}=9)$, were in the treatment pen for $<7$ or $>35 \mathrm{~d}$ before giving birth (as we expected that these cows may not have experienced the treatment as we intended; $\mathrm{n}=11$ and $\mathrm{n}=1$, respectively), had a lameness score $>3(\mathrm{n}=$ 3 ; measured at study enrollment, the day of calving, and $14 \mathrm{~d}$ after calving using a 1-to-5 scale described by Flower and Weary, 2006, where flat back and all legs bear weight equally $=1$; flat or mildly arched back and slightly asymmetric gait $=2$; arched back and slight $\operatorname{limp}=3$; clearly arched back and reluctant to bear weight on at least $1 \operatorname{limb}=4$; extremely arched back and inability to bear weight on 1 or more limbs $=5$ ), were diagnosed with mastitis before calving $(\mathrm{n}=2$; cows were diagnosed by farm personnel), were unable to use the chute for blood sample and hygiene analysis $(\mathrm{n}=1)$, or calved in the wrong treatment pen by accident $(\mathrm{n}=1)$.

The remaining 324 cows were included in the final hygiene and metritis analysis (primiparous $=115$, multiparous $=209)$ in the treatment pens with high stocking density and no blind $(\mathrm{n}=83)$, high stocking density pens with a blind $(\mathrm{n}=84)$, low stocking density pens $(\mathrm{n}=79)$, and low stocking density pens without a blind $(\mathrm{n}=78)$. The subsample of animals selected for further blood analysis $(n=206)$ were selected from this population of animals.

\section{Statistical Analysis}

Analyses were performed with SAS software (version 9.4). Raw data were visually screened for data distribution and outliers using the UNIVARIATE procedure in SAS. Treatment was applied at the pen level, so pen was considered the unit of analysis $(\mathrm{n}=16)$, and cow was considered the observational unit. In all statistical 
models, the random term "period $\times$ stocking density $\times$ blind" is included to identify the pen as the experimental unit of analysis (St-Pierre, 2007; Bello et al., 2016). This methodology is explained in more detail in St-Pierre (2007) and Bello et al. (2016). Statistical significance was declared at $P<0.05$ and tendencies at $P<0.10$. All data were screened for normality of residuals after analysis. Serum biomarkers (NEFA, $\mathrm{BHB}$, and haptoglobin) were natural log-transformed to normalize the error distribution. Parity (primiparous vs. multiparous) was initially included in all models as a main effect. However, after preliminary analysis, we detected no interactions between parity and our treatments; thus, parity is included only in models with a significant main effect $(P<0.05)$. Body condition score at enrollment and calving (as a continuous variable) were included as covariates in all models, excluding hygiene, for pre- and postpartum outcomes, respectively. Interactions between treatment and BCS were tested and retained where significant. All possible interactions were tested; however, only significant interactions $(P$ $<0.05)$ were in included in final statistical models. No significant interactions were detected unless otherwise stated.

To determine the effects of our factors and their interaction on serum biomarkers (NEFA, BHB, and haptoglobin) linear mixed models were conducted using the MIXED procedure of SAS. Data collected before calving $(\mathrm{d}-14,-7)$ and after calving $(\mathrm{d} 3,7,10,14)$ were analyzed separately. Prepartum models included the baseline value (day of enrollment, $\mathrm{d}-23.6 \pm 5.8$ ) for each biomarker as a covariate; main effects included day $(-14,-7)$, stocking density (high vs. low), and blind (yes vs. no), and all significant interactions. A heterogeneous autoregressive covariance structure was chosen based on best fit, using the Bayesian information criterion to account for the correlation in the errors across different days. Postpartum models for analysis of NEFA and BHB included main effects of day $(3,7,10$, and 14), stocking density, blind, parity, and all interactions. Postpartum models for analysis of haptoglobin included main effects of day $(3,7,10$, and 14$)$, stocking density, blind, parity, assisted calving (unassisted vs. assisted), and all significant interactions. Assisted calving was included in the postpartum haptoglobin model because it is a known covariate (Huzzey et al., 2009). A spatial power covariance structure was used to model the correlation on the errors across days. For both pre- and postpartum models, random effects included period (1 to 4 ) and a period $\times$ stocking density $\times$ blind interaction.

To determine the effects of our factors and their interaction on subclinical ketosis (diagnosed vs. not diagnosed), a generalized linear mixed model was used, using the GLIMMIX procedure of SAS. A logistic mixed effects model was used, with main effects including stocking density (high vs. low), blind (yes vs. no), parity (primiparous vs. multiparous), and all significant interactions. Random effects included period (1 to 4 ) and a period $\times$ stocking density $\times$ blind interaction.

To determine the effect of our factors and their interaction on metritis (none, mild, or severe), a generalized linear mixed model was performed using the GLIMMIX procedure of SAS. A proportional odds mixed effects model with a cumulative logit link function was used, with main effects in the model included for stocking density (high vs. low), blind (yes vs. no), retained placenta (yes vs. no), assisted calving (unassisted vs. assisted), and all significant interactions. Random effects included period ( 1 to 4 ) and a period $\times$ stocking density $\times$ blind interaction.

Hygiene scores from a single observer were used for hygiene analysis. Effects of each factor and their interaction on hygiene score were again analyzed with a proportional odds mixed model with a cumulative logit link function, using the GLIMMIX procedure of SAS. Only 1 score of 4 was assigned, which was combined with scores of 3 , resulting in 3 hygiene scores $(1,2$, or 3). Main effects in the model included baseline hygiene score (day of enrollment, $\mathrm{d}-23.6 \pm 5.8$ ) as a covariate, stocking density (high vs. low), blind (yes vs. no), and all significant interactions. Random effects included period (1-4) and a period $\times$ stocking density $\times$ blind interaction.

\section{RESULTS}

\section{Serum Biomarkers}

Before calving, cows housed in pens with a blind had lower haptoglobin compared with cows housed in pens without a blind (Table 1). We did not observe an effect of stocking density on prepartum haptoglobin concentrations. We found no effect of stocking density or blind, nor an interaction, on NEFA or BHB concentrations.

After calving, we found no effect of stocking density or blind on NEFA, BHB, or haptoglobin (Table 1), nor did we find any interaction between the factors. We did detect some parity effects, whereby primiparous animals had lower NEFA [log-transformed LSM (backtransformed LSM are in parentheses) \pm SE: -0.94 (0.39 $\mathrm{mmol} / \mathrm{L})$ vs. $-0.66(0.51 \mathrm{mmol} / \mathrm{L}) \pm 0.05 ; P<0.001]$, BHB $[-0.43(0.65 \mathrm{mmol} / \mathrm{L})$ vs. $-0.15(0.86 \mathrm{mmol} / \mathrm{L})$ $\pm 0.06 ; P<0.001]$, and greater haptoglobin concentrations $[-0.76(0.47 \mathrm{~g} / \mathrm{L})$ vs. $-1.02(0.36 \mathrm{~g} / \mathrm{L}) \pm 0.05 ; P$ 
Table 1. Log-transformed LSM \pm SE for pre- and postpartum concentrations of nonesterified fatty acids (NEFA), BHB, and haptoglobin for 206 Holstein dairy cows housed in group bedded-pack pens for approximately 3 wk before calving at high versus low stocking density $(\mathrm{n}=103$ and 103, respectively), with or without provision of a calving blind ( $\mathrm{n}=102$ and 104 , respectively), sampled weekly ${ }^{1}$

\begin{tabular}{|c|c|c|c|c|c|c|c|c|}
\hline Variable & \multicolumn{4}{|c|}{ Stocking density } & \multicolumn{4}{|c|}{ Blind } \\
\hline \multicolumn{9}{|c|}{ NEFA $[\log (\mathrm{mmol} / \mathrm{L})]$} \\
\hline Postpartum & $-0.79(0.45)$ & $-0.81(0.44)$ & 0.06 & 0.78 & $-0.80(0.45)$ & $-0.81(0.45)$ & 0.06 & 0.92 \\
\hline \multicolumn{9}{|c|}{ BHB $[\log (\mathrm{mmol} / \mathrm{L})]$} \\
\hline Prepartum & $-1.04(0.35)$ & $-1.07(0.34)$ & 0.04 & 0.28 & $-1.04(0.35)$ & $-1.07(0.34)$ & 0.04 & 0.35 \\
\hline Postpartum & $-0.95(0.39)$ & $-0.84(0.43)$ & 0.05 & 0.14 & $-0.90(0.41)$ & $-0.88(0.41)$ & 0.05 & 0.81 \\
\hline
\end{tabular}

${ }^{1}$ Cows in pens with high and low stocking density had approximately $7.7-12.9 \mathrm{~m}^{2}$ and $15.4-25.8 \mathrm{~m}^{2}$ of lying space per cow, respectively. Data that were log-transformed (NEFA, BHB, and haptoglobin) are back-transformed in parentheses.

$<0.001]$ than multiparous cows after calving. We also found that animals with assisted calvings had higher haptoglobin than those with unassisted calvings $[-0.77$ $(0.46 \mathrm{~g} / \mathrm{L})$ vs. $-1.01(0.36 \mathrm{~g} / \mathrm{L}) \pm 0.05 ; P=0.002]$. Finally, NEFA, BHB, and haptoglobin decreased as DIM increased $(P<0.001)$.

\section{Hygiene}

High stocking density increased the odds of having a hygiene score of 2 or 3 compared with low stocking density (Table 2). We detected no effect of blind on the odds of having poorer hygiene, and no interaction between our factors.

\section{Disease}

We detected no effect of the presence or absence of the blind on the likelihood of mild or severe metritis diagnosis (Table 3). Cows housed in low prepartum stocking density pens tended to have a greater odds of being diagnosed with metritis than cows in high prepartum stocking density pens. Animals had a higher likelihood of metritis if they had an assisted calving or retained placenta.

A total of $37.9 \%(78 / 206)$ of cows tested for subclinical ketosis had at least 1 postpartum BHB measure $\geq$ $1.2 \mathrm{mmol} / \mathrm{L}$. We did not detect an effect of stocking density [odds ratio (OR; 95\% CI in parentheses) $=1.15$ $(0.51,2.55) ; P=0.71]$ or presence of a blind [OR $(95 \%$ $\mathrm{CI})=0.73(0.33,1.62) ; P=0.39]$ on the likelihood of subclinical ketosis. Multiparous cows were more likely to develop subclinical ketosis than primiparous cows $[$ OR $(95 \%$ CI $)=1.97(1.03,3.74) ; P=0.04]$.

Supplemental Files S1-S4 are available at https:// doi.org/10.3168/jds.2020-18718.

\section{DISCUSSION}

Our objective was to determine the effects of stocking density and the provision of a blind in bedded-pack pens on inflammatory (haptoglobin) and metabolic

Table 2. Hygiene scores of 318 Holstein dairy cows housed in group bedded-pack pens for approximately 3 wk before calving at high versus low stocking density $\left(\mathrm{n}=164\right.$ and 154 , respectively), with or without provision of a calving blind $\left(\mathrm{n}=157\right.$ and 161 , respectively), scored weekly ${ }^{1}$

\begin{tabular}{|c|c|c|c|c|c|c|}
\hline \multirow[b]{2}{*}{ Variable } & \multicolumn{3}{|c|}{ Hygiene score $^{2}$} & \multirow[b]{2}{*}{$\mathrm{OR}^{3}$} & \multirow[b]{2}{*}{$95 \%$ CI } & \multirow[b]{2}{*}{$P$-value } \\
\hline & 1 & 2 & $3^{4}$ & & & \\
\hline \multicolumn{7}{|l|}{ Stocking density } \\
\hline High & $31(157 / 503)$ & $58(290 / 503)$ & $11(56 / 503)$ & 2.51 & $1.11-5.82$ & 0.03 \\
\hline Low & $48(242 / 501)$ & $48(238 / 501)$ & $4(21 / 501)$ & Referent & & \\
\hline \multicolumn{7}{|l|}{ Blind } \\
\hline Pen with blind & $37(188 / 505)$ & $55(278 / 505)$ & $8(39 / 505)$ & 0.65 & $0.29-1.50$ & 0.28 \\
\hline
\end{tabular}

${ }^{1}$ Cows in pens with high and low stocking density had approximately $7.7-12.9 \mathrm{~m}^{2}$ and $15.4-25.8 \mathrm{~m}^{2}$ of lying space per cow, respectively.

${ }^{2}$ Expressed as a percentage of scores during the prepartum period (number of scores/total scoring events in parentheses).

${ }^{3}$ Odds ratio; odds of poorer hygiene score.

${ }^{4}$ Hygiene score 3 included all scores of 3 and 2 scores of 4 (high stocking density $=1$, pen with blind $=1$ ). 
Table 3. Logistic regression model describing the effect of stocking density (high stocking density $=164$ vs. low stocking density $=154)$ and presence of calving blind (pen with blind $=157$ vs. pen without blind $=161$ ) on metritis diagnosis (none, mild, or severe) 0 to $14 \mathrm{~d}$ after calving $^{1}$

\begin{tabular}{|c|c|c|c|c|c|c|}
\hline \multirow[b]{2}{*}{ Variable } & \multicolumn{3}{|c|}{ Metritis diagnosis $^{2}$} & \multirow[b]{2}{*}{$\mathrm{OR}^{3}$} & \multirow[b]{2}{*}{$95 \% \mathrm{CI}$} & \multirow[b]{2}{*}{$P$-value } \\
\hline & None & Mild & Severe & & & \\
\hline \multicolumn{7}{|l|}{ Stocking density } \\
\hline Low & 40 & 50 & 10 & 1.64 & $0.99-2.70$ & 0.051 \\
\hline High & 52 & 36 & 12 & Referent & & \\
\hline \multicolumn{7}{|l|}{ Blind } \\
\hline Pen with blind & 45 & 40 & 15 & 1.35 & $0.78-2.33$ & 0.22 \\
\hline No blind & 47 & 45 & 8 & Referent & & \\
\hline \multicolumn{7}{|l|}{ Assisted calving } \\
\hline Assisted & 24 & 56 & 20 & 4.07 & $2.49-6.64$ & $<0.0001$ \\
\hline Unassisted & 55 & 37 & 8 & Referent & & \\
\hline \multicolumn{7}{|l|}{ Retained placenta } \\
\hline Yes & 9 & 62 & 29 & 6.40 & $2.70-15.19$ & $<0.0001$ \\
\hline No & 49 & 41 & 10 & Referent & & \\
\hline
\end{tabular}

${ }^{1}$ Cows were housed in group bedded-pack maternity pens during the $3 \mathrm{wk}$ before calving. Cows in pens with high and low stocking density had approximately $7.7-12.9 \mathrm{~m}^{2}$ and $15.4-25.8 \mathrm{~m}^{2}$ of lying space per cow, respectively. Covariates in the final logistic regression included assisted calving (human intervention $=95$ vs. no human intervention $=224$ ) and retained placenta (failure to release fetal membranes within $24 \mathrm{~h}$ of calving $=$ 21 vs. no retained placenta $=297)$.

${ }^{2}$ Expressed as the percentage of cows diagnosed with no, mild, or severe metritis during the $14 \mathrm{~d}$ after calving within their defined category (stocking density, blind, assisted calving, retained placenta).

${ }^{3}$ Odds ratio; odds of more severe metritis diagnosis.

(NEFA, BHB) biomarkers, subclinical ketosis, metritis, and hygiene of periparturient dairy cows. We found that our treatments affected some outcomes, but these effects depended on the period relative to calving, and the biological significance of these effects are unclear. During the prepartum period, haptoglobin was lower in pens with a blind. In addition, prepartum animals were had higher odds of having worse hygiene scores in high stocking density pens. Postpartum, we detected a tendency for greater likelihood of metritis for cows housed in low compared with high stocking density pens prepartum; however, this result is difficult to interpret due to low sample size.

Before calving, animals in pens without a blind had higher haptoglobin concentrations compared with those in pens with a blind prepartum. As calving approaches, cows are motivated to isolate from herdmates using distance on pasture (Flörcke and Grandin, 2014) and manmade fixtures in individual (Proudfoot et al., 2014b) and group maternity pens (Rørvang et al., 2018). Despite these studies demonstrating a preference for visually isolating from other cows at calving, research has yet to document the physiological impact of performing motivated behaviors at calving in dairy cows. Research in swine suggests that restricting maternal behaviors may lead to increased stress responses; for example, sows in farrowing crates that are unable to perform nest-building behavior have increased respiration rates (Heckt et al., 1988) and plasma cortisol (Lawrence et al., 1997). Acute and chronic stress responses have been linked to changes in inflammation in humans (reviewed by Rohleder, 2014), but it is unclear whether this same mechanism drives the increase in haptoglobin found in our study.

We detected no effect of stocking density on prepartum haptoglobin concentrations. These results are consistent with previous research focused on prepartum cows housed in freestall pens, which has been unable to establish a connection between prepartum housing and haptoglobin. For example, Proudfoot et al. (2018) found no differences in haptoglobin throughout the transition period for cows exposed to predictable or unpredictable feeding environments. Miltenburg et al. (2018) were also unable to detect a difference in haptoglobin levels -3 to 5 wk relative to calving in $80 \%$ versus $120 \%$ prepartum stocking density treatments. Haptoglobin is an acute-phase protein that is stimulated by proinflammatory cytokines (Baumann and Gauldie, 1994) and is used as an indicator of inflammation in dairy cattle. Alterations in lying space in this study may not have been substantial enough to cause a chronic inflammatory response reflected by haptoglobin (Horadagoda et al., 1999).

No differences were detectable between treatments for NEFA throughout the pre- and postpartum periods. For stocking density, these results are consistent with a previous study using minor differences in the stocking density of freestall pens ( $80 \%$ vs. $100 \%$; Silva et al., 2014). Increased NEFA has been thought to be a consequence of reduced feed intake as cows begin to mo- 
bilize fat to compensate for negative energy imbalance (Bauman and Currie, 1980). Prepartum cows in our study had designated individual feeding bins regardless of stocking density, which may have contributed to the lack of differences in metabolic biomarkers, compared with other stocking density studies in pre- and postpartum cows (Huzzey et al., 2012; Proudfoot et al., 2018). For example, Huzzey et al. (2012) found that cows in overstocked pens (200\% stocking: 0.5 lying stalls per cow and $34.5 \mathrm{~cm}$ linear feed bunk space per cow) had higher circulating NEFA and glucose concentrations during the early dry period compared with cows that were not overstocked (100\% stocking: 1 lying stall per cow and 68.5 linear feed bunk space per cow). Additionally, Proudfoot et al. (2018) found that cows in unpredictable feeding environments (2 cows per feeding bin and feed delivery time changed on alternating days) had slightly higher NEFA concentrations throughout the transition period compared with cows in predictable feeding environments ( 6 cows per 4 feeding bins and consistent feeding time). The results of this study are novel in that stocking density of lying space was altered but not feeding space. It is possible that by not overstocking cows at the feed bunk, the feeding behavior between treatment pens was unaltered, leading to a lack of differences in NEFA concentration.

We did not detect any differences between high and low stocking density pens in BHB concentrations during the pre- or postpartum periods, nor subclinical ketosis following calving. $\beta$-Hydroxybutyrate is used as an indicator of ketosis during the first few weeks after calving (McArt et al., 2012). Increased blood ketones following calving are thought to be an adaptation to the negative energy balance triggered by the onset of lactation, but high ketone levels are abnormal and predispose cows to disease and reduced reproductive efficiency (Walsh et al., 2007; Duffield et al., 2009). Consistent with our results, Miltenburg et al. (2018) also found no difference in pre- or postpartum BHB levels for cows that were housed in under- $(0.8$ cows per lying stall and $90 \mathrm{~cm}$ feed bunk space per cow) or overstocked freestalls (1.2 cows per lying stall and $45 \mathrm{~cm}$ feed bunk space per cow) during the $3 \mathrm{wk}$ before calving. Average postpartum BHB concentrations in our study were low in all treatments (ranging from 0.73 to $0.77 \mathrm{mmol} / \mathrm{L}$ ), well below the cutoff for subclinical ketosis $(\geq 1.2 \mathrm{mmol} / \mathrm{L}$; McArt et al., 2012). Additionally, $37.9 \%$ of postpartum cows in this study were classified as having subclinical ketosis ( 1 or more of the 4 postpartum blood samples $\geq 1.2$ $\mathrm{mmol} / \mathrm{L}$ ), which is lower than incidences reported in previous research, of approximately 43 to $44 \%$ of cows with subclinical ketosis (McArt et al., 2012; Kaufman et al., 2016). In commercial dairies, feedbunk and lying space stocking density are usually related, and overstocking in lying space would likely result in overstocking at the feedbunk. Kaufman et al. (2016) did not report feedbunk stocking density but found that increasing stall stocking by $5 \%$ during the week before calving increased the risk of ketosis by $10 \%$. Changes in lying space did not affect BHB or rates of ketosis in our study; however, there may have been some unintended benefits of keeping feed bunk stocking density consistent across treatments.

We did not find any effect of the blind on NEFA, BHB, or subclinical ketosis. Despite a lack of benefits from pens containing a blind on metabolic biomarkers and subclinical ketosis, it is important to note that inclusion of the blind in a bedded-pack pen did not have any unintended negative consequences. Thus, in a practical setting, the addition of manmade blinds to create physical and visual separation from other cows in group bedded-pack pens could allow cows to perform natural calving behaviors without negative health effects.

The presence or absence of a blind did not affect the likelihood of metritis; however, we detected a tendency for higher odds of metritis in low compared with high stocking density pens. Few studies have measured the influence of stocking density on metritis risk in dairy cows. One study using freestall pens found no effect of increasing stocking density at the feedbunk and lying stalls from 80 to $100 \%$ on the incidence of metritis (Silva et al., 2014). Metritis is a common disease in dairy cows, affecting 10 to $30 \%$ of cows (Giuliodori et al., 2013) within $21 \mathrm{~d}$ after calving. Many cows are able to clear metritis with uterine involution and proper functioning of the immune system, unless accompanied by other system signs of systemic illness such as fever and depression (Sheldon et al., 2006). It is unclear why cows in low stocking density pens tended to be more likely to develop metritis than in high stocking density pens; however, this trend seems to be largely influenced by the mild metritis diagnosis. A greater percentage of cows from low stocking density pens were diagnosed with mild metritis compared with cows in high stocking density pens, but the difference was minimal. The number of cows diagnosed as not having metritis $(52 \%$ vs. $40 \%$ of cows in high vs. low stocking density pens, respectively) were similar, and the results should not be overinterpreted. We offer one potential explanation, that cows in low stocking density pens before calving may have experienced greater stress when transitioning into the postcalving pen because the difference in space allowance was more substantial compared with those in high stocking density pens before calving.

Cows in high stocking density pens had poorer hygiene compared with those in low stocking density pens, but no effect of the blind on hygiene was detectable. The lying environment is the primary source of 
contact between cows, moisture, and manure. Previous research suggests that hygiene scores worsen in openpack-housed cows when bedding conditions become wetter (Chen et al., 2017). Additionally, poor hygiene in lactating cows puts cows at greater risk of risk of developing subclinical mastitis (Reneau et al., 2005; Dohmen et al., 2010) due to increased contact with moisture and manure. Despite poorer hygiene scores in the high stocking density pens, the majority of observations were considered clean, with the majority of hygiene scores categorized as clean (hygiene score $1=$ $39.3 \%$ and $2=52.9 \%$ of observations) and the fewest observations categorized as dirty (hygiene score $3=$ $7.8 \%$ of observations). Poorer hygiene in high stocking density pens was likely due to increased urine, manure, and birth fluids per square meter of lying space because high stocking density pens contained the same number of cows but half the bedded-pack space of low stocking density pens. Throughout the course of this study, pens received clean sawdust bedding every other day and were completely cleaned every 3 to $4 \mathrm{wk}$. In this case, a low overall hygiene scores were likely attributable to good pen management and the provision of sufficient bedding.

Parity had some influence on serum biomarkers and subclinical ketosis after calving. Postpartum, primiparous cows had lower concentrations of NEFA and BHB and were less likely to develop subclinical ketosis, but no interactions between parity and treatments were observed. A lack of treatment differences between parity before calving may indicate that differences after calving were influenced by the postpartum environment, which was beyond our scope, so we may only speculate on the differences. Concentrations of NEFA and BHB around calving are frequently used for predicting risk of disease and culling. Roberts et al. (2012) found that in the 2 wk postpartum, multiparous cows with high NEFA and BHB had higher odds of being culled, but for primiparous cows the risk of culling was unaffected for NEFA and BHB concentrations. Similarly, Ospina et al. (2010b) found that an increase in NEFA and BHB during the 2 wk after calving was associated with decreased milk production in multiparous cows and increased milk in primiparous cows. Collectively, these studies suggest that primiparous cows may have a different physiological response to metabolic challenges after calving because they have additional growth requirements in addition to milk production.

After calving, primiparous cows had greater haptoglobin concentrations than multiparous cows. Although a statistical difference was found between parity for haptoglobin concentrations, the concentrations for both primiparous $(0.47 \mathrm{~g} / \mathrm{L})$ and multiparous cows $(0.36$ $\mathrm{g} / \mathrm{L}$ ) were well under the cut points used to predict disease after calving ( $>0.8 \mathrm{~g} / \mathrm{L}$, Dubuc et al., 2010; 1 $\mathrm{g} / \mathrm{L}$, Huzzey et al., 2009). The low value of postpartum haptoglobin suggests that both primiparous and multiparous cows may have been in good overall health.

A main limitation of this study was potentially not having the appropriate power to detect differences in health outcomes (metritis and subclinical ketosis) between treatments. At the start of the study, a simple power analysis was conducted to estimate the number of cows needed to assess differences in health and behavior outcomes (behavioral outcomes will be presented in a separate paper). However, in the end, our analysis was more complex than our original power analysis, which may have underestimated the number of cows needed to assess differences in disease outcomes (e.g., metritis). Thus, we caution the interpretation of disease outcomes from the study and strongly encourage that future studies attempt to replicate our findings using a larger sample size. In addition, due to the nature of transition cow research, we were unable to completely control for stocking density, as cows' actual calving dates varied from their expected calving date. For this reason, there were occasions when lying space per cow was greater than anticipated due to cows calving before their expected calving date. We still feel confident that we created 2 distinctive stocking density treatments and used methodology similar to others facing this same challenge (Silva et al., 2014; Miltenburg et al., 2018). It would have been possible to enroll cows more frequently than once per week to keep stocking density at a more consistent rate, but we chose against this option in order not to confound the treatments with regrouping stress caused by entering new cows into pen every few days. Moreover, the weekly addition of new cows to pens is a common management practice on many dairy farms. Adding new cows to our treatment pens once per week more closely simulated commercial conditions than if new cows were entered every few days.

\section{CONCLUSIONS}

Increased stocking density and the provision of a blind had minor effects on cow physiology and health. Before calving, the provision of a blind resulted in lower signs of inflammation (haptoglobin). However, neither stocking density nor provision of a blind affected metabolic biomarkers (NEFA and BHB) before or after calving. Overall, animals had better hygiene in pens with lower stocking density. However, after calving we found slight increases in the likelihood of metritis for cows previously kept in lower-stocked pens. Providing more space in bedded-pack pens before calving resulted in cleaner cows, and the provision of the blind resulted in 
minor reductions in inflammation; however, the biological relevance of these results remains unknown.

\section{ACKNOWLEDGMENTS}

We sincerely thank the research and farm staff of the William H. Miner Agricultural Research Institute (Chazy, NY) for their help with animal care and data collection throughout the study, without which this project would not have been possible. This study was funded by USDA-NIFA grant no. 2016-67015-24734 (Washington, DC). The authors have not stated any conflicts of interest.

\section{REFERENCES}

Bauman, D. E., and W. B. Currie. 1980. Partitioning of nutrients during pregnancy and lactation: A review of mechanisms involving homeostasis and homeorhesis. J. Dairy Sci. 63:1514-1529. https:// doi.org/10.3168/jds.S0022-0302(80)83111-0.

Baumann, H., and J. Gauldie. 1994. The acute phase response. Immunol. Today 15:74-80. https://doi.org/10.1016/0167-5699(94)90137 -6 .

Bello, N. M., M. Kramer, R. J. Tempelman, W. W. Stroup, N. R. St-Pierre, B. A. Craig, L. J. Young, and E. E. Gbur. 2016. Short communication: On recognizing the proper experimental unit in animal studies in the dairy sciences. J. Dairy Sci. 99:8871-8879. https://doi.org/10.3168/jds.2016-11516.

Chen, J. M., C. L. Stull, D. N. Ledgerwood, and C. B. Tucker. 2017. Muddy conditions reduce hygiene and lying time in dairy cattle and increase time spent on concrete. J. Dairy Sci. 100:2090-2103. https://doi.org/10.3168/jds.2016-11972.

Cook, N. B. 2007. A toolbox for assessing cow, udder and teat hygiene. Pages 31-43 in Proc. 46th Annu. Mtg. Natl. Mastitis Counc., San Antonio, TX. National Mastitis Council, Madison, WI.

Dohmen, W., F. Neijenhuis, and H. Hogeveen. 2010. Relationship between udder health and hygiene on farms with an automatic milking system. J. Dairy Sci. 93:4019-4033. https://doi.org/10.3168/ jds.2009-3028.

Dubuc, J., T. F. Duffield, K. E. Leslie, J. S. Walton, and S. J. LeBlanc. 2010. Risk factors for postpartum uterine diseases in dairy cows. J. Dairy Sci. 93:5764-5771. https://doi.org/10.3168/jds.2010-3429.

Duffield, T. F., K. D. Lissemore, B. W. McBride, and K. E. Leslie. 2009. Impact of hyperketonemia in early lactation dairy cows on health and production. J. Dairy Sci. 92:571-580. https://doi.org/ 10.3168/jds.2008-1507.

Elbers, A. R. W., J. D. Miltenburg, D. DeLange, A. P. P. Crauwels, H. W. Barkema, and Y. H. Schukken. 1998. Risk factors for clinical mastitis in a random sample of dairy herds from the southern part of the Netherlands. J. Dairy Sci. 81:420-426. https://doi.org/10 .3168/jds.S0022-0302(98)75592-4.

Ferguson, J. D., D. T. Galligan, and N. Thomsen. 1994. Principal descriptors of body condition score in Holstein cows. J. Dairy Sci. 77:2695-2703.

Flörcke, C., and T. Grandin. 2014. Separation behavior for parturition of Red Angus beef cows. Open J. Anim. Sci. 4:43-50. https://doi .org/10.4236/ojas.2014.42007.

Flower, F. C., and D. M. Weary. 2006. Effect of hoof pathologies on subjective assessments of dairy cow gait. J. Dairy Sci. 89:139-146. https://doi.org/10.3168/jds.S0022-0302(06)72077-X.

Genís, S., R. L. A. Cerri, À. Bach, B. F. Silper, M. Baylão, J. DenisRobichaud, and A. Arís. 2018. Pre-calving intravaginal administration of lactic acid bacteria reduces metritis prevalence and regulates blood neutrophil gene expression after calving in dairy cattle. Front. Vet. Sci. 5:135. https://doi.org/10.3389/fvets.2018.00135.
Giuliodori, M. J., R. P. Magnasco, D. Becu-Villalobos, I. M. LacauMengido, C. A. Risco, and R. L. de la Sota. 2013. Metritis in dairy cows: Risk factors and reproductive performance. J. Dairy Sci. 96:3621-2631. https://doi.org/10.3168/jds.2012-5922.

Heckt, W. L., R. M. Widowski, S. E. Curtis, and H. W. Gonyou. 1988. Prepartum behavior of gilts in three farrowing environments. J. Anim. Sci. 66:1378-1385. https://doi.org/10.2527/jas1988 .6661378x.

Horadagoda, N. U., K. M. G. Knox, H. A. Gibbs, S. W. J. Reid, A. Horadagoda, S. E. R. Edwards, and P. D. Eckersall. 1999. Acute phase proteins in cattle: Discrimination between acute and chronic inflammation. Vet. Rec. 144:437-441. https://doi.org/10.1136/vr .144.16.437.

Huzzey, J. M., T. F. Duffield, S. J. LeBlanc, D. M. Veira, D. M. Weary, and M. A. G. von Keyserlingk. 2009. Short communication: Haptoglobin as an early indicator of metritis. J. Dairy Sci. 92:621-625. https://doi.org/10.3168/jds.2008-1526.

Huzzey, J. M., R. J. Grant, and T. R. Overton. 2012. Short communication: Relationship between competitive success during displacements at an overstocked feed bunk and measures of physiology and behavior in Holstein dairy cattle. J. Dairy Sci. 95:4434-4441. https://doi.org/10.3168/jds.2011-5038.

Kaufman, E. I., S. J. LeBlanc, B. W. McBride, R. F. Duffield, and T. J. DeVries. 2016. Association of rumination time with subclinical ketosis in transition dairy cows. J. Dairy Sci. 99:5604-5618. https: //doi.org/10.3168/jds.2015-10509.

Lawrence, A. B., K. A. McLean, S. Jarvis, C. L. Gilbert, and J. C. Petherick. 1997. Stress and parturition in the pig. Reprod. Domest. Anim. 32:231-236. https://doi.org/10.1111/j.1439-0531 1997.tb01287.x.

Lidfors, L. M., D. Moran, J. Jung, P. Jensen, and H. Castren. 1994. Behaviour at calving and choice of calving place in cattle kept in different environments. Appl. Anim. Behav. Sci. 42:11-28. https:/ /doi.org/10.1016/0168-1591(94)90003-5.

McArt, J. A. A., D. V. Nydam, and G. R. Oetzel. 2012. Epidemiology of subclinical ketosis in early lactation dairy cattle. J. Dairy Sci. 95:5056-5066. https://doi.org/10.3168/jds.2012-5443.

Miltenburg, C. L., T. F. Duffield, D. Bienzle, E. L. Scholtz, and S. J. LeBlanc. 2018. The effect of prepartum feeding and lying space on metabolic health and immune function. J. Dairy Sci. 101:52945306. https://doi.org/10.3168/jds.2017-13481.

Ospina, P. A., D. V. Nydam, T. Stokol, and T. R. Overton. 2010a. Evaluation of nonesterified fatty acids and $\beta$-hydroxybutyrate in transition dairy cattle in the northeastern United States: Critical thresholds for prediction of clinical diseases. J. Dairy Sci. 93:546554. https://doi.org/10.3168/jds.2009-2277.

Ospina, P. A., D. V. Nydam, T. Stokol, and T. R. Overton. 2010b. Associations of elevated nonesterified fatty acids and $\beta$-hydroxybutyrate concentrations with early lactation reproductive performance and milk production in transition dairy cattle in the northeastern United States. J. Dairy Sci. 93:1596-1603. https: //doi.org/10.3168/jds.2009-2852.

Proudfoot, K., and G. Habing. 2015. Social stress as a cause of diseases in farm animals: Current knowledge and future directions. Vet. J. 206:15-21. https://doi.org/10.1016/j.tvjl.2015.05.024.

Proudfoot, K. L., M. B. Jensen, D. M. Weary, and M. A. G. von Keyserlingk. 2014b. Dairy cows seek isolation at calving and when ill. J. Dairy Sci. 97:2731-2739. https://doi.org/10.3168/jds.2013 -7274 .

Proudfoot, K. L., D. M. Weary, S. J. LeBlanc, K. Mamedova, and M. A. G. von Keyserlingk. 2018. Exposure to an unpredictable and competitive social environment affects behavior and health of transition dairy cows. J. Dairy Sci. 101:9309-9320.

Proudfoot, K. L., D. M. Weary, and M. A. G. von Keyserlingk. 2014a. Maternal isolation behavior of Holstein dairy cows kept indoors. J. Anim. Sci. 92:277-281. https://doi.org/10.2527/jas.2013-6648.

Reneau, J. K., M. S. Anthony, J. Seykora, B. J. Heins, M. I. Endres, R. J. Farnsworth, and R. F. Bey. 2005. Association between hygiene scores and somatic cell scores in dairy cattle. J. Am. Vet. Med. Assoc. 227:1297-1301. https://doi.org/10.2460/javma.2005.227.1297. 
Roberts, T., N. Chapinal, S. J. LeBlanc, D. F. Kelton, J. Dubuc, and T. F. Duffield. 2012. Metabolic parameters in transition cows as indicators for early-lactation culling risk. J. Dairy Sci. 95:30573063.

Rohleder, N. 2014. Stimulation of systemic low-grade inflammation by psychosocial stress. Psychosom. Med. 76:181-189. https://doi.org/ 10.1097/PSY.0000000000000049.

Rørvang, M. V., M. S. Herskin, and M. B. Jensen. 2018. The motivation-based calving facility: Social and cognitive factors influence isolation seeking behavior of Holstein dairy cows at calving. PLoS One 13:e0191128. https://doi.org/10.1371/journal.pone.0191128.

Sheldon, I. M., G. S. Lewis, S. LeBlanc, and R. O. Gilbert. 2006. Defining postpartum uterine disease in cattle. Theriogenology 65:1516-1530. https://doi.org/10.1016/j.theriogenology.2005.08 .021 .

Silva, P. R. B., A. R. Dresch, K. S. Machado, J. G. N. Moraes, K. Lobeck-Luchterhand, T. K. Nishimura, M. A. Ferreira, M. I. Endres, and R. C. Chebel. 2014. Prepartum stocking density: Effects on metabolic, health, reproductive, and productive responses. J. Dairy Sci. 97:5521-5532. https://doi.org/10.3168/jds.2014-8093.
St-Pierre, N. R. 2007. Design and analysis of pen studies in animal sciences. J. Dairy Sci. 90(E-Suppl.):E87-E99.

USDA. 2016. Dairy 2014: Dairy Cattle Management Practices in the United States. USDA-Anim. Plant Health Insp. Serv.-Vet. Serv., Center Epidemiol. Anim. Health, Natl. Anim. Health Monit. Syst., Fort Collins, CO.

Walsh, R. B., J. S. Walton, D. F. Kelton, S. J. LeBlanc, K. E. Leslie, and T. F. Duffield. 2007. The effect of subclinical ketosis in early lactation on reproductive performance of postpartum dairy cows. J. Dairy Sci. 90:2788-2796. https://doi.org/10.3168/jds.2006-560.

\section{ORCIDS}

K. C. Creutzinger (ํ) https://orcid.org/0000-0002-6237-5145

H. M. Dann (® https://orcid.org/0000-0002-7372-7011

L. E. Moraes (ㄴ) https://orcid.org/0000-0002-0179-6093

P. D. Krawczel $\odot$ https://orcid.org/0000-0002-9867-2280

K. L. Proudfoot @ https://orcid.org/0000-0001-5877-2431 